OPEN ACCESS

Edited by:

Yuli Huang,

Southern Medical University, China

Reviewed by: Yi Wang,

Zhejiang University, China Linda Zhong, Hong Kong Baptist University, Hong Kong

*Correspondence: Fengqin Xu 18800021979@163.com

Yue Liu

liuyueheart@hotmail.com

${ }^{\dagger}$ These authors share first authorship

Specialty section: This article was submitted to Cardiovascular Metabolism, a section of the journal

Frontiers in Cardiovascular Medicine

Received: 20 December 2020 Accepted: 19 January 2021 Published: 24 February 2021

Citation:

Cui J, LiU Y, Li Y, Xu F and LiU Y (2021) Type 2 Diabetes and Myocardial Infarction: Recent Clinical Evidence and Perspective.

Front. Cardiovasc. Med. 8:644189. doi: $10.3389 / f c v m .2021 .644189$

\section{Type 2 Diabetes and Myocardial Infarction: Recent Clinical Evidence and Perspective}

\author{
Jing Cui ${ }^{1,2+}$, Yanfei Liu ${ }^{3 \dagger}$, Yiwen $\mathrm{Li}^{1,2,4}$, Fengqin $\mathrm{Xu}^{2,4 *}$ and Yue Liu ${ }^{1,2,4 *}$ \\ ${ }^{1}$ Cardiovascular Centre of Xiyuan Hospital, China Academy of Chinese Medical Sciences, Beijing, China, ${ }^{2}$ National Clinical \\ Research Centre for Chinese Medicine Cardiology, Beijing, China, ${ }^{3}$ Institute of Clinical Pharmacology, Xiyuan Hospital of \\ China Academy of Chinese Medical Sciences, Beijing, China, ${ }^{4}$ China Center for Evidence-Based Medicine of Chinese \\ Medicine, Beijing, China
}

Type 2 diabetes mellitus (T2DM) and its complications are seriously affecting public health worldwide. Myocardial infarction (MI) is the primary cause of death in patients with T2DM. T2DM patients without a history of coronary artery disease (CAD) have the same risk of major coronary events as those with CAD; T2DM patients with a history of $\mathrm{Ml}$ have $>40 \%$ risk of recurrence of Ml. Thus, CAD in patients with T2DM needs to be treated actively to reduce the risk of Ml. The cardiology community focused on the role of T2DM in the development of CAD and on the related issues of T2DM and $\mathrm{Ml}$ with respect to comorbidities, prognosis, drug therapy, and heredity. In this mini review, the latest progress of clinical evidence-based research between T2DM and Ml in recent years was reviewed, and the possible research directions in this field were considered and prospected.

Keywords: type 2 diabetes, myocardial infarction, evidence-based medicine, drug, sodium-glucose cotransporter2 inhibitor

\section{INTRODUCTION}

Type 2 diabetes mellitus (T2DM) is one of the leading chronic non-communicable disease, and its prevalence has significantly increased globally. In 2017, the prevalence of adult T2DM accounted for $8.8 \%$ of the world population, and this proportion is expected to increase to $9.9 \%$ by $2045(1,2)$. With the increasing number of cases, T2DM and its complications are seriously affecting the quality of human life and have become a serious global public health problem. A pooled analysis of 22 prospective cohort studies encompasses more than one million subjects in Asia found that Asian patients with T2DM are at a higher risk of death than patients from the Western countries, with an $89 \%$ increase in mortality compared with that of those without T2DM (3). China has become a "hardest hit area" by T2DM; among Chinese adults, the estimated overall prevalence of T2DM is $10.9 \%$, and the prevalence of pre-T2DM is $35.7 \%$ (4). Myocardial infarction (MI) is the primary cause of death in T2DM patients, and the risk of major coronary events in T2DM patients without a history of coronary artery disease (CAD) is equal to that in patients with CAD, with the $>20 \%$ risk of a first MI within 10 years of developing T2DM, which is equal to the risk of a second MI within 10 years in non-T2DM patients with a history of MI, while the risk of recurrence of MI in the future in T2DM patients with MI history exceeds $40 \%$ (5). In a scientific statement published in Circulation on April 13, 2020 (6), the American Heart Association (AHA) noted that compared with CAD in patients without T2DM, CAD in patients with T2DM needs to be treated more aggressively to reduce the risk of MI. Although cardiologists have been treating patients with CAD and associated 
T2DM for a long time, T2DM has traditionally been considered a comorbidity that only affects the development and progression of the CAD. In the past decade, many factors have changed, forcing the cardiology community to reconsider the important role of T2DM in the development and progression of CAD. In addition to being associated with increased cardiovascular (CV) risk, T2DM may influence the choice of multiple treatments for CAD. Thus, glycemic control is recommended as part of the comprehensive risk factor management for patients with CAD; there has been growing evidence that the mechanisms of glycemic control have a significant impact on CV outcomes (7).

With the publication of the results of several large clinical trials on oral hypoglycemic drugs with CV benefits in recent years, people are more concerned about the comorbidities, prognosis, drug treatment, genetics, and other issues related to T2DM and $\mathrm{MI}$.

In this review article, by mainly retrieving PubMed, MEDLINE, EMBASE, and Web of Science, we identified and critically analyzed nearly 5 years (from January 1, 2016, until December 30, 2020) of published clinical studies [randomized controlled trials (RCTs) and cohort studies] focusing on T2DM and MI. The search terms were "diabetes, type 2 diabetes mellitus, myocardial infarction, MI, cardiovascular disease, cardiovascular safety, cardiovascular events, cardiovascular risk, cardiovascular outcomes." The retrieval formula was appropriately adapted to different databases.

In this paper, the latest progress in evidence-based clinical research on T2DM and $\mathrm{MI}$ in recent years has been reviewed, and the possible research directions in this field in the future have been considered and prospected.

\section{COMORBID FEATURES OF TYPE 2 DIABETES MELLITUS AND MYOCARDIAL INFARCTION}

In 2019, the Guidelines on Diabetes, Pre-Diabetes and Cardiovascular Diseases jointly issued by the European Society of Cardiology (ESC) and European Association for the Study of Diabetes (EASD) recommends that all patients with cardiovascular disease should be screened for T2DM and that patients with cardiovascular disease complicated by T2DM should undergo comprehensive risk factor management, including control of blood pressure, serum glucose, and lipid levels; management of antiplatelet therapy regimens; and lifestyle interventions (8). The trends of mortality and morbidity in MI patients after 1 year suggested that long-term trends in survival and CV outcomes have improved considerably in patients with MI; however, their risk of mortality and morbidity in MI remains higher than that of the general population, especially when additional risk factors such as T2DM, hypertension, or advanced age are present $(9,10)$.

The prevalence of unrecognized abnormal glucose tolerance (AGT) and the incidence of recurrent CV events in patients with MI have not been systematically assessed. A meta-analysis of the prevalence of AGT in MI patients without a history of $\mathrm{DM}$ as well as the risk of recurrent major adverse cardiac events
(MACEs) and mortality in MI patients was conducted. In the 19 clinical studies included ( $n=541,509$ with a median followup of 3.1 years), the prevalence of newly discovered AGT in patients with MI was $48.4 \%$. Patients with prediabetes had a higher risk of death and MACE than did patients with normal glucose tolerance (NGT). Newly diagnosed T2DM cases showed a higher risk of death and MACE occurrence than NGT cases (11). Clinical research on the prevalence and prognosis of MI in asymptomatic T2DM patients has also been conducted to determine the prevalence of unrecognized MI in asymptomatic T2DM patients using delayed-enhancement MRI (DE-MRI), and the results of up to 5 years of follow-up in 460 T2DM patients showed that the incidence of death or MI was significantly higher in unidentified T2DM patients and that unidentified MI was prevalent in asymptomatic T2DM patients without a history of heart disease (12).

Researchers are increasingly concerned about the relationship between prediabetes and the risk of CV disease (CVD) and mortality (13-15). A meta-analysis of the association between prediabetes and the risk of CVD and mortality including 129 studies with a total of $10,069,955$ patients showed that prediabetes increased risk of all-cause mortality and CVD and that prevention of prediabetes was important for patients with CVD (16).

A systematic review and meta-analysis of the correlation between T2DM and long-term ( $\geq 1$ year) post-MI mortality was conducted, including $10 \mathrm{RCTs}$ and 56 cohort studies $(714,780$ patients), with a total of 202,411 deaths over a median follow-up time of 2.0 (range, 1-20) years; it was found that the high longterm mortality of patients with T2DM was significant over time, independent of the phenotype of MI and modern treatments, and the long-term mortality was approximately 50\% higher in patients with T2DM than in those without T2DM (17). Patients with T2DM had worse short- and long-term prognoses than those without T2DM, and undiagnosed T2DM was significantly correlated with higher mortality, especially in patients still with undiagnosed T2DM at the time of hospital admission (5).

Intracoronary drug-eluting stent (DES) percutaneous coronary intervention (PCI) is currently one of the standard treatments for patients with acute coronary syndrome (ACS), including those with $\mathrm{MI}$, and T2DM also has a negative impact on the treatment and outcome of patients after PCI. Earlystage arterial healing after DES-PCI makes short-term dual antiplatelet therapy (DAPT) possible. A study (18) used coronary angiography [coronary artery stenosis (CAS)] data to compare the intravascular status of T2DM patients $(n=149)$ and nonT2DM patients $(n=188)$ in the early post-DES-PCI period, and it found that 3-5 months after DES implantation, DM patients showed more uncovered stent wires than non-DM patients, suggesting that the recent ultrashort DAPT strategy may not be applicable to patients with concomitant T2DM. Meanwhile, new-onset T2DM [new onset of DM (NODM)] after DES-PCI is receiving increasing attention. A study (19) used a retrospective cohort design to report the incidence, predictors, and long-term clinical outcomes of NODM after DES-PCI in patients with MI. The study reviewed 6,048 patients after PCI, grouped according to the presence or absence of T2DM before PCI, and found 
that $436(11.8 \%)$ of 3,683 patients with ACS who did not have a diagnosis of T2DM before PCI had developed NODM over the $3.4 \pm 1.9$ years of follow-up, with independent predictors including high-dose statin therapy, high body mass index (BMI), and high fasting plasma glucose (FPG) and triglyceride levels. The cumulative MACE rate over 8 years of follow-up were significantly lower in the group with NODM after PCI (19.5\%) than in the group with preoperatively diagnosed T2DM $(25 \%, P$ $=0.003)$ and comparable with the group without T2DM $(20.5 \%$, $P=0.467)$. A retrospective cohort study conducted in Taiwan that included a larger number of patients (20) (30,665 patients diagnosed with ACS undergoing PCI) found a significant $27 \%$ increased risk of NODM in patients using statins than in those not using statins. The benefits of statins in preventing morbidity and mortality in patients with ACS have been validated in several clinical trials, and the clinical decision to recommend statin therapy for patients with pre-existing CVD should not be altered.

Knowledge about the mechanisms responsible for diabetes accelerating MI has increased enormously in recent years. The mechanisms by which hyperglycemia and insulin resistance increased mortality after MI were increasingly understood (21). Most diabetic patients are complicated with insulin resistance, hyperinsulinemia, and vascular calcification, which not only promote the occurrence of atherosclerosis but also accelerate the progression of stable plaques to unstable plaques or plaque rupture leading to thrombosis, thus leading to the occurrence of coronary adverse events (22). Contributing factors [including diabetes-induced overexpression of reactive oxygen species (ROS); secretion of inflammatory cytokines; increased aldose reductase (AKR1B1) substrate conversion; and activation of protein kinase $C \beta, \delta$, and $\theta$ ] accelerate the occurrence of MI (21).

Not only is T2DM strongly associated with MI, but its complications are also closely related with MI. A systematic review and meta-analysis of cohort studies on association between diabetic retinopathy (DR) and CVD included a total of 13 studies representing 17,611 patients, which suggested that $\mathrm{DR}$ is remarkably related with increased risk of CVD and CVDassociated mortality in diabetes (23). In addition, a hospitalbased cross-sectional study in China included 949 patients (700 males and 249 females) with T2DM both non-proliferative DR (NPDR) and proliferative DR (PDR) independently associated with increased cardio-ankle vascular index (CAVI) (24). Other studies have also shown that central atherosclerosis is associated with the presence and severity of DR in patients with T2DM (25).

It is generally acknowledged that T2DM is an independent risk factor of acute kidney injury (AKI). Meanwhile, AKI predicts poor prognosis in patients with MI. The data from a multicenter factorial RCT included 10,251 participants who showed an incremental graded risk for CVD outcomes and all-cause mortality with the development of chronic kidney disease (CKD) and/or CVD in individuals with T2DM (26). Experimental evidence suggests that treatment with the sodiumglucose cotransporter-2 (SGLT2) inhibitor protects the diabetic kidney from MI-induced AKI (27).

\section{SHIFT FROM "CARDIOVASCULAR SAFETY" TO "CARDIORENAL BENEFIT" OF ORAL HYPOGLYCEMIC AGENTS}

The discovery and clinical application of insulin as well as the subsequent introduction of various oral hypoglycemic agents (OHAs) have greatly prolonged the survival time of T2DM patients and transformed T2DM into a major chronic noncommunicable disease. The effect of CV-related complications on the prognosis of patients with T2DM has attracted more attention and finally became the primary problem to be solved in improving the clinical prognosis of patients with T2DM. Few large-scale CV outcome trials (CVOTs) have been conducted to verify the CV safety of traditional OHAs. Since 2007, when rosiglitazone was found to significantly increase the risk of MI in T2DM patients (28), the CV safety of OHAs has received more attention. In 2008, the US Food and Drug Administration (FDA) developed a guidance document (29) to clarify the CV safety of innovative OHAs for the treatment of T2DM, which requires clinical evaluation of $\mathrm{CV}$ safety for all agents used for the treatment of T2DM prior to marketing. Therefore, CVOTs have been conducted for all OHAs marketed after 2008 to evaluate their CV safety.

SGLT2 inhibitor is an innovative oral hypoglycemic drug marketed in recent years, and its main mechanism of action is to lower blood glucose by inhibiting the reabsorption of glucose by the renal proximal convoluted tubules and promoting urinary glucose excretion. In 2015, the results of the EMPA-REG OUTCOME trial $(30,31)$ were published, making empagliflozin the first oral hypoglycemic drug with definite CV benefits. In T2DM patients with comorbid CVDs, empagliflozin significantly reduced the risk of three-point MACE (3P-MACE) by $14 \%$, and the risk of $\mathrm{CV}$ death and hospitalization for heart failure (HF) by 38 and 35\%, respectively. Over the past 5 years, results from several large clinical trials on SGLT2 inhibitors have been published $(30,32-38)$ (see Table 1), and the expectation for OHAs has gradually changed from "cardiovascular safety" to "cardiovascular benefits." Among the renal outcome studies, EMPA-REG OUTCOME was the first to report a $39 \%$ reduction in the risk of developing a renal composite endpoint with empagliflozin, suggesting that empagliflozin may delay the progression of renal diseases (39). A clinical study evaluating the effect of canagliflozin on renal events of patients with DM complicated by renal diseases with renal outcomes as a primary endpoint also demonstrated that canagliflozin reduced the risk of composite endpoints by up to $30 \%$ (34). The therapeutic focus of T2DM has also changed, from an exclusive focus on glucoselowering parameters, to comprehensive management, and then to the current therapeutic focus on cardiac benefits and renal outcomes (see Figure 1).

SGLT2 inhibitors exhibited superiority; thus, the cardiologist approve that SGLT2 inhibitors should be used in great property, at least in T2DM patients with high $\mathrm{CV}$ risk (40). What is more, major international guidelines all highly recommend the use (or combined use) of SGLT2 inhibitors in patients with T2DM with comorbid CVDs (or high risk 
TABLE 1 | Characteristics of the RCT studies about SGLT2 inhibitors.

\begin{tabular}{|c|c|c|c|c|c|c|c|c|}
\hline Clinical trials & $\begin{array}{l}\text { EMPA-REG } \\
\text { outcome (30) }\end{array}$ & CANVAS (32) & $\begin{array}{l}\text { DECLARE- } \\
\text { TIMI } 58 \text { (33) }\end{array}$ & Credence (34) & DAPA-HF (35) & $\begin{array}{l}\text { Emperor- } \\
\text { reduced (36) }\end{array}$ & Vertis (37) & DAPA-CKD (38) \\
\hline $\begin{array}{l}\text { ClinicalTrials.gov } \\
\text { number }\end{array}$ & NCT01131676 & $\begin{array}{l}\text { NCT01032629/ } \\
\text { NCT01989754 }\end{array}$ & NCT01730534 & NCT02065791 & NCT03036124 & NCT03057977 & NCT01986881 & NCT03036150 \\
\hline Year & 2015 & 2017 & 2019 & 2019 & 2019 & 2020 & 2020 & 2020 \\
\hline Participants (n) & 7,020 & 10,142 & 17,160 & 4,401 & 4,744 & 3,730 & 8,246 & 4,304 \\
\hline Age, years (mean) & 63.1 & 63 & 63.9 & 63 & 66 & 67 & 64 & 62 \\
\hline Men (\%) & 71.2 & 64.9 & 63.1 & 66 & 77 & 76 & 70 & 67 \\
\hline $\begin{array}{l}\text { SGLT2 inhibitor } \\
\text { agent }\end{array}$ & Empagliflozin & Canagliflozin & Dapagliflozin & Canagliflozin & Dapagliflozin & Empagliflozin & Ertugliflozin & Dapagliflozin \\
\hline Dose $\left(\mathrm{mg} \cdot \mathrm{day}^{-1}\right)$ & 10,25 & 100,300 & 10 & 100 & 10 & 10 & 5,15 & 10 \\
\hline Eligibility criteria & $\begin{array}{c}\geq 18 \text { years of age; } \\
\text { clinical diagnosis of } \\
\text { type } 2 \text { diabetes; } \\
\text { established } \\
\text { cardiovascular } \\
\text { disease, glycated } \\
\text { hemoglobin level of } \\
7 \sim 10 \%, \text { eGFR } \geq 30 \\
\mathrm{ml} \cdot \mathrm{min}^{-1} \cdot(1.73 \\
\left.\mathrm{m}^{2}\right)^{-1}\end{array}$ & $\begin{array}{l}\geq 30 \text { years of age with a } \\
\text { history of symptomatic } \\
\text { atherosclerotic } \\
\text { cardiovascular disease or } \\
\geq 50 \text { years of age with two } \\
\text { or more of the following } \\
\text { risk factors for } \\
\text { cardiovascular disease: } \\
\text { clinical diagnosis of type } 2 \\
\text { diabetes; glycated } \\
\text { hemoglobin level } \\
7.0 \sim 10.5 \%, \text { eGFR } \geq 30 \\
\text { m. } \text { min }^{-1} \cdot\left(1.73 \mathrm{~m}^{2}\right)^{-1}\end{array}$ & $\begin{array}{c}\geq 40 \text { years of age; } \\
\text { clinical diagnosis of } \\
\text { type } 2 \text { diabetes; } \\
\text { multiple risk factors } \\
\text { for atherosclerotic } \\
\text { cardiovascular } \\
\text { disease or had } \\
\text { established } \\
\text { atherosclerotic } \\
\text { cardiovascular } \\
\text { disease glycated } \\
\text { hemoglobin level } \\
6.5 \sim 12 \% ; \text { creatinine } \\
\text { clearance } \geq 60 \\
\text { ml.min }\end{array}$ & $\begin{array}{l}\geq 30 \text { years of age; } \\
\text { clinical diagnosis of } \\
\text { type } 2 \text { diabetes; } \\
\text { glycated hemoglobin } \\
\text { level of } 6.5-12.0 \% \text {; } \\
\text { eGFR } 30 \sim 90 \\
\mathrm{ml} \cdot \mathrm{min}^{-1} \cdot(1.73 \\
\left.\mathrm{m}^{2}\right)^{-1} \text {; urine } \\
\text { albumin: creatinine } \\
\text { ratio } 300 \sim 5,000 \\
\mathrm{mg} \cdot \mathrm{g}^{-1}\end{array}$ & $\begin{array}{c}\geq 18 \text { years of age; New } \\
\text { York Heart Association } \\
\text { (NYHA) class II, III, or IV } \\
\text { symptoms, ejection } \\
\text { fraction } \leq 40 \% \text {; } \\
\mathrm{NT} \text {-proBNP } \geq 600 \\
\mathrm{pg} \cdot \mathrm{ml}^{-1} \text { (or } \geq 400 \\
\mathrm{pg} \cdot \mathrm{ml}^{-1} \text { if they had been } \\
\text { hospitalized for heart } \\
\text { failure within the previous } \\
12 \text { months, or NT-proBNP } \\
\geq 900 \mathrm{pg} \cdot \mathrm{ml}^{-1} \text { if they are } \\
\text { with atrial fibrillation or } \\
\text { atrial flutter on baseline } \\
\text { electrocardiography } \\
\text { regardless of their history } \\
\text { of hospitalization for heart } \\
\text { failure) }\end{array}$ & $\begin{array}{c}\geq 18 \text { years of age; } \\
\text { NYHA class II, III, or } \\
\text { IV symptoms; } \\
\text { ejection fraction } \leq \\
40 \%\end{array}$ & $\begin{array}{c}\geq 40 \text { years of age; } \\
\text { clinical diagnosis of } \\
\text { type } 2 \text { diabetes; } \\
\text { established } \\
\text { atherosclerotic } \\
\text { cardiovascular } \\
\text { disease involving the } \\
\text { coronary, } \\
\text { cerebrovascular, or } \\
\text { peripheral arterial } \\
\text { systems; glycated } \\
\text { hemoglobin level of } \\
7 \sim 10.5 \%\end{array}$ & $\begin{array}{c}\geq 18 \text { years of age, } \\
\text { eGFR } 25 \sim 75 \\
\mathrm{ml} \cdot \mathrm{min}^{-1} \cdot(1.73 \\
\left.\mathrm{m}^{2}\right)^{-1} \text {, urine } \\
\text { albumin: creatinine } \\
\text { ratio } 200 \sim 5,000 \\
\mathrm{mg} \cdot \mathrm{g}^{-1}\end{array}$ \\
\hline $\begin{array}{l}\text { Follow-up, years } \\
\text { (median) }\end{array}$ & 3.1 & 2.4 & 4.2 & 2.6 & 1.5 & 1.3 & 3 & 2.4 \\
\hline $\begin{array}{l}\text { Percentage of } \\
\text { patients with } \\
\text { confirmed } \\
\text { cardiovascular } \\
\text { disease at baseline } \\
\text { (\%) }\end{array}$ & 99.4 & 71.2 & 40.5 & 50.4 & 100 & 100 & 76.1 & 37.4 \\
\hline $\begin{array}{l}\text { Percentage of } \\
\text { patients with heart } \\
\text { failure at baseline (\%) }\end{array}$ & 9.9 & 14 & 9.9 & 15 & 100 & 100 & 24 & 11 \\
\hline $\begin{array}{l}\text { Proportion of } \\
\text { patients with eGFR } \\
\geq 30 \mathrm{ml}^{-} \mathrm{min}^{-1} \cdot(1.73 \\
\left.\mathrm{m}^{2}\right)^{-1} \text { at baseline } \\
(\%)\end{array}$ & 74.2 & 76.7 & 85.4 & 100 & 100 & - & 100 & 85.5 \\
\hline
\end{tabular}

Albumin-to-creatinine ratio was calculated with albumin measured in milligrams and creatinine measured in grams.

SGLT2, sodium-glucose cotransporter-2; eGFR, estimated glomerular filtration rate; NT-proBNP, N-terminal pro-B-type natriuretic peptide; RCT, randomized controlled trial. 


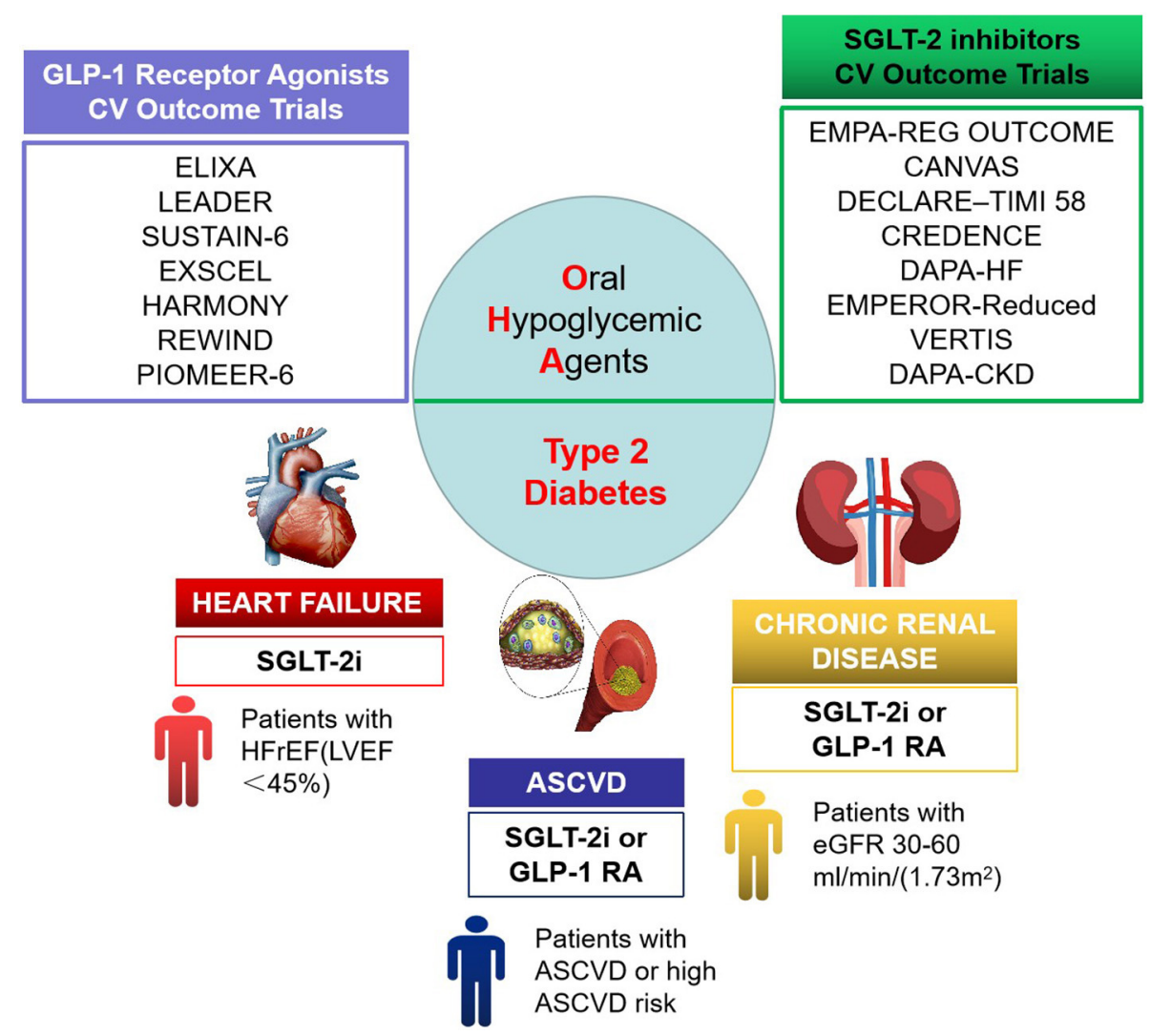

FIGURE 1 | Cardiorenal benefit of oral hypoglycemic agents in therapeutic focus of type 2 diabetes mellitus (T2DM).

of CVDs) and/or CKD, with the ESC/EASD guidelines (7) recommending them over metformin in newly diagnosed patients. The overall degree of recommendation by the American Association of Clinical Endocrinology/American College of Endocrinology (AACE/ACE) guidelines (41) is comparable with that for metformin.

Dipeptidyl peptidase-4 (DPP-4) inhibitors also occupy an increasing place in the management of T2DM. DPP-4 inhibitors may enhance homing of endothelial progenitor cells and thereby exert vascular protection (42). Available evidence suggests that DPP-4 inhibitors have a weak CV protective effect (43). However, in clinical application, it should be selected according to the actual situation. In patients with T2DM with advanced CVD or $\mathrm{HF}$ associated with renal function deterioration, DPP-4 inhibitors appear to be safe to use from a cardiological point of view, and SGLT2 inhibitors are contraindication (44). Of note, a study based on a large diabetic cohort of 113,051 T2DM patients showed that DPP-4 inhibitors as a second- or third-line add-on treatment provided CV benefits and posed no increased risks for HF, hypoglycemia, or death (45).

Glucagon-like peptide-1 receptor agonists (GLP-1 RAs) is viewed as the primary DPP-4 substrate capable of modulating CV function. The study found that use of GLP-1 RAs was associated with significant reductions in CV and all-cause mortality, and the researchers suggested that GLP-1 RAs should be used as a first-line treatment in patients with T2DM at higher CV risk or as a first-line treatment in patients with metformin resistance (46).

\section{PERSPECTIVE}

\section{Exploration of Early-Stage Screening Methods}

The comprehensive management of T2DM patients is important for early identification and detection of possible CV risks. An effective risk prediction model was established by Chinese scholars, and it was found that weight reduction, lowering blood pressure and blood uric acid levels, and proper control of diastolic blood pressure could significantly reduce the risk of new-onset ACS in T2DM patients in northwest China (47). The meta-analysis included 30 studies with 253,425 participants and $1,621,920$ person-years of follow-up, which is about prognosis of unrecognized MI determined by electrocardiography or cardiac MRI. Unrecognized myocardial infarction (UMI) by electrocardiography (ECG) or UMI by cardiac MR (CMR) is associated with an adverse long-term prognosis similar to that of recognized MI (48). Imaging evidence indicates a high prevalence of CAD in patients with T2DM; however, there is no standard for initiating CAD screening in the T2DM population, and it has been found that routine screening for CAD using 
computed tomographic coronary angiography (CTCA) should be considered for early detection of CAD in asymptomatic T2DM patients with diagnosed duration of T2DM $>10.5$ years and systolic blood pressure $>140 \mathrm{mmHg}$ (49). A study (50) has established the triglyceride glucose index (TGI), calculated as [fasting triglycerides $\left(\mathrm{mg} \cdot \mathrm{dl}^{-1}\right) \times \mathrm{FPG}\left(\mathrm{mg} \cdot \mathrm{dl}^{-1}\right) / 2$ ], to predict $\mathrm{CV}$ events and demonstrated that TGI may be a better predictor for the risk of CV events than FPG or glycosylated hemoglobin (HbA1c) in patients with ACS undergoing PCI. Statins have been widely used for lipid-lowering therapy in patients with CAD; however, there has been increasing clinical evidence of a correlation between statin use and NODM. A study (51) found that systolic epicardial adipose tissue thickness is an independent predictor for NODM in patients with CAD treated with highintensity statins, which can help physicians formulate timely and appropriate monitoring or intervention plans for the early detection of NODM.

\section{Exploration From a Genetic Perspective}

Scholars have conducted useful exploration on which T2DM patients are more likely to develop MI from a genetic perspective. The common MTNR1B single-nucleotide polymorphism locus rs10830963 is strongly correlated with the risk of developing T2DM. The relationship between this genetic variation and the risk of MI in patients with T2DM has been investigated using data from a UK Biobank cohort, which investigated the relationship between rs10830963 and the incidence of MI (fatal and non-fatal) in 13,655 participants with possible T2DM over a 6.8-year followup period. With the use of an additive genetic model, variation in the MTNR1B gene rs10830963 was found to be positively correlated with the risk of developing MI over 6.8 years of followup, suggesting that rs10830963 polymorphism may be a useful genetic marker for the development of MI in patients with T2DM (52). The growing knowledge of the genetic insights between T2D and CVD is beginning to provide the potential understanding of both disorders (53). In the future, the subtle relationship between T2DM and MI can be explored further deeply in terms of genetics.

\section{Diversity of Drug Evaluation Methods}

In the clinical evaluation of the $\mathrm{CV}$ safety of innovative oral hypoglycemic drugs, although RCTs can better exclude the influences of confounding factors, they have poor external validity and cannot fully meet the actual clinical needs. Therefore, combining RCTs with real-world research/study (RWR/RWS) can provide more reliable and high-level clinical evidence, and

\section{REFERENCES}

1. Standl E, Khunti K, Hansen TB, Schnell O. The global epidemics of diabetes in the 21st century: current situation and perspectives. Eur J Prev Cardiol. (2019) 26:7-14. doi: 10.1177/2047487319881021

2. Cho NH, Shaw JE, Karuranga S, Huang Y, da Rocha Fernandes JD, Ohlrogge AW, et al. IDF Diabetes Atlas: global estimates of diabetes prevalence for 2017 and projections for (2045). Diabetes Res Clin Pract. (2018) 138:27181. doi: 10.1016/j.diabres.2018.02.023 real-world evidence (RWE) studies can be used as auxiliary evidence to RCTs to evaluate the efficacy and safety of drugs, which can help fill the knowledge gap between RCTs and actual clinical practice (54). RCTs provide evidence for clinical guideline recommendations, and real-world studies test the practicability of guideline recommendations, thus allowing stepby-step refinement of treatment strategies to optimize treatment and return to clinical practice. RWS includes a wider population to compensate for the poor external validity of RCTs due to stringent inclusion and exclusion criteria. A credible RWS covers a large number of patients and can reflect the routine clinical practice, which is of clinical significance for treatment and especially for safety assessment.

Moreover, SGLT2 inhibitors have been used to treat patients with T2DM to reduce the risk of $\mathrm{CV}$ events, including $\mathrm{HF}$, and it is clear that the mechanism by which SGLT2 inhibitors reduce this risk may not be directly related to improved diabetic status and glycemic control. In addition, short-term use of SGLT2 inhibitors significantly improved volume load and symptoms in HF patients with concomitant T2DM; however, serum N-terminal pro-B-type natriuretic peptide (NT-proBNP) concentrations, which are traditionally used to assess HF severity, did not improve significantly, suggesting that we need to explore meaningful biomarkers that can monitor and evaluate the effect SGLT2 inhibitors for HF treatment in the future (55), in order to provide scientific evidence for in-depth understanding of the many unknowns of SGLT2 inhibitors.

\section{AUTHOR CONTRIBUTIONS}

JC and YaL formed the reference collection, conducted the reference analysis, and wrote the manuscript and are considered as co-first authors. YuL and FX contributed to the topic conception, manuscript revision, and decision to submit for publication and are the co-corresponding authors. YiL contributed to reference analysis and helped in the revision of the manuscript. All authors contributed to the article and approved the submitted version.

\section{FUNDING}

This work was supported by the Outstanding Youth Foundation of National Natural Science Foundation (82022076) and the Special Project for Outstanding Young Talents of China Academy of Chinese Medical Sciences (ZZ13-YQ-001 and ZZ13-YQ-001-A1).
3. Yang JJ, Yu D, Wen W, Saito E, Rahman S, Shu XO, et al. Association of diabetes with all-cause and cause-specific mortality in asia: a pooled analysis of more than 1 million participants. JAMA Netw Open. (2019) 2:e192696. doi: 10.1001/jamanetworkopen.2019.2696

4. Wang L, Gao P, Zhang M, Huang Z, Zhang D, Deng Q, et al. Prevalence and ethnic pattern of diabetes and prediabetes in China in (2013). JAMA. (2017) 317:2515-23. doi: 10.1001/jama.2017.7596

5. Avogaro A, Bonora E, Consoli A, Del Prato S, Genovese S, Giorgino F. Glucose-lowering therapy and cardiovascular outcomes in patients with type 
2 diabetes mellitus and acute coronary syndrome. Diab Vasc Dis Res. (2019) 16:399-414. doi: 10.1177/1479164119845612

6. Arnold SV, Bhatt DL, Barsness GW, Beatty AL, Deedwania PC, Inzucchi SE, et al. Clinical management of stable coronary artery disease in patients with type 2 diabetes mellitus: a scientific statement from the american heart association. Circulation. (2020) 141:e779-806. doi: 10.1161/CIR.0000000000000766

7. Yang CT, Yang CY, Ou HT, Kuo S. Comparative cardiovascular safety of GLP-1 receptor agonists versus other glucose-lowering agents in real-world patients with type 2 diabetes: a nationwide population-based cohort study. Cardiovasc Diabetol. (2020) 19:83. doi: 10.1186/s12933-020-01053-0

8. Cosentino F, Grant PJ, Aboyans V, Bailey CJ, Ceriello A, Delgado V, et al. (2019). ESC Guidelines on diabetes, pre-diabetes, cardiovascular diseases developed in collaboration with the EASD. Eur Heart J. (2020) 41:255-323. doi: 10.1093/eurheartj/ehz486

9. Johansson S, Rosengren A, Young K, Jennings E. Mortality and morbidity trends after the first year in survivors of acute myocardial infarction: a systematic review. BMC Cardiovasc Disord. (2017) 17:53. doi: 10.1186/s12872-017-0482-9

10. Schmitt VH, Hobohm L, Munzel T, Wenzel P, Gori T, Keller K. Impact of diabetes mellitus on mortality rates and outcomes in myocardial infarction. Diabetes Metab. (2020). doi: 10.1016/j.diabet.2020.11.003. [Epub ahead of print].

11. Laichuthai N, Abdul-Ghani M, Kosiborod M, Parksook WW, Kerr SJ, DeFronzo RA. Newly discovered abnormal glucose tolerance in patients with acute myocardial infarction and cardiovascular outcomes: a meta-analysis. Diabetes Care. (2020) 43:1958-66. doi: 10.2337/dc20-0059

12. Elliott MD, Heitner JF, Kim H, Wu E, Parker MA, Lee DC, et al. Prevalence and prognosis of unrecognized myocardial infarction in asymptomatic patients with diabetes: a two-center study with up to 5 years of follow-up. Diabetes Care. (2019) 42:1290-6. doi: 10.2337/dc18-2266

13. Wang $\mathrm{T}, \mathrm{Lu}$ J, Su Q, Chen Y, Bi Y, Mu Y, et al. Ideal cardiovascular health metrics and major cardiovascular events in patients with prediabetes and diabetes. JAMA Cardiol. (2019) 4:874-83. doi: 10.1001/jamacardio.2019.2499

14. Hubbard D, Colantonio LD, Tanner RM, Carson AP, Sakhuja S, Jaeger BC, et al. Prediabetes and risk for cardiovascular disease by hypertension status in black adults: the jackson heart study. Diabetes Care. (2019) 42:23229. doi: $10.2337 / \mathrm{dc} 19-1074$

15. Warren B, Pankow JS, Matsushita K, Punjabi NM, Daya NR, Grams $M$, et al. Comparative prognostic performance of definitions of prediabetes: a prospective cohort analysis of the Atherosclerosis Risk in Communities (ARIC) study. Lancet Diabetes Endocrinol. (2017) 5:34-42. doi: 10.1016/S2213-8587(16)30321-7

16. Cai X, Zhang Y, Li M, Wu JH, Mai L, Li J, et al. Association between prediabetes and risk of all cause mortality and cardiovascular disease: updated meta-analysis. BMJ. (2020) 370:m2297. doi: 10.1136/bmj.m2297

17. Gholap NN, Achana FA, Davies MJ, Ray KK, Gray L, Khunti K. Long-term mortality after acute myocardial infarction among individuals with and without diabetes: a systematic review and meta-analysis of studies in the post-reperfusion era. Diabetes Obes Metab. (2017) 19:36474 doi: $10.1111 /$ dom. 12827

18. Ishihara $\mathrm{T}$, Sotomi $\mathrm{Y}$, Tsujimura $\mathrm{T}$, Iida $\mathrm{O}$, Kobayashi $\mathrm{T}$, Hamanaka $\mathrm{Y}$, et al. Impact of diabetes mellitus on the early-phase arterial healing after drug-eluting stent implantation. Cardiovasc Diabetol. (2020) 19:203. doi: 10.1186/s12933-020-01173-7

19. Chun KH, Im E, Kim BK, Shin DH, Kim JS, Ko YG, et al. Incidence, predictors, and clinical outcomes of new-onset diabetes mellitus after percutaneous coronary intervention with drug-eluting stent. J Korean Med Sci. (2017) 32:1603-9. doi: 10.3346/jkms.2017.32.10.1603

20. Lin ZF, Wang CY, Shen LJ, Hsiao FY, Lin Wu FL. Statin use and the risk for incident diabetes mellitus in patients with acute coronary syndrome after percutaneous coronary intervention: a population-based retrospective cohort study in Taiwan. Can J Diabetes. (2016) 40:2649. doi: 10.1016/j.jcjd.2015.12.006

21. Shah MS, Brownlee M. Molecular and cellular mechanisms of cardiovascular disorders in diabetes. Circulation Res. (2016) 118:1808-29. doi: 10.1161/CIRCRESAHA.116.306923
22. Yuan T, Yang T, Chen H, Fu D, Hu Y, Wang J, et al. New insights into oxidative stress and inflammation during diabetes mellitus-accelerated atherosclerosis. Redox Biol. (2019) 20:247-60. doi: 10.1016/j.redox.2018. 09.025

23. Guo VY, Cao B, Wu X, Lee JJW, Zee BC. Prospective association between diabetic retinopathy and cardiovascular disease-a systematic review and meta-analysis of cohort studies. J Stroke Cerebrovasc Dis. (2016) 25:168895. doi: 10.1016/j.jstrokecerebrovasdis.2016.03.009

24. Zhang $\mathrm{C}$, Wang $\mathrm{S}, \mathrm{Li} \mathrm{M}, \mathrm{Wu} \mathrm{Y}$. Association between atherosclerosis and diabetic retinopathy in chinese patients with type 2 diabetes mellitus. Diabetes Metab Syndr Obes. (2020) 13:1911-20. doi: 10.2147/DMSO.S246497

25. Zhang X, Lim SC, Tavintharan S, Yeoh LY, Sum CF, Ang K, et al. Association of central arterial stiffness with the presence and severity of diabetic retinopathy in Asians with type 2 diabetes. Diabetes Vasc Dis Res. (2019) 16:498505. doi: 10.1177/1479164119845904

26. Branch M, German C, Bertoni A, Yeboah J. Incremental risk of cardiovascular disease and/or chronic kidney disease for future ASCVD and mortality in patients with type 2 diabetes mellitus: ACCORD trial. J Diabetes Complications. (2019) 33:468-72. doi: 10.1016/j.jdiacomp.2019.04.004

27. Kuno A, Kimura Y, Mizuno M, Oshima H, Sato T, Moniwa N, et al. Empagliflozin attenuates acute kidney injury after myocardial infarction in diabetic rats. Sci Rep. (2020) 10:7238. doi: 10.1038/s41598-020-64380-y

28. Nissen SE, Wolski K. Effect of rosiglitazone on the risk of myocardial infarction and death from cardiovascular causes. N Engl J Med. (2007) 356:2457-71. doi: 10.1056/NEJMoa072761

29. Guidance for Industry: Diabetes mellitus-evaluating cardiovascular risk in new antidiabetic therapies to treat type 2 diabetes [EB / OL]. Available online at: www.fda.gov/downloads/drugs/ guidancecomplianceregulataryinformation/guidances/ucm071627.pdf (accessed August 30, 2019).

30. Zinman B, Wanner C, Lachin JM, Fitchett D, Bluhmki E, Hantel S, et al. Empagliflozin, cardiovascular outcomes, and mortality in type 2 diabetes. $N$ Engl J Med. (2015) 373:2117-28. doi: 10.1056/NEJMoa1504720

31. Fitchett D, Zinman B, Wanner C, Lachin JM, Hantel S, Salsali A, et al. Heart failure outcomes with empagliflozin in patients with type 2 diabetes at high cardiovascular risk: results of the EMPA-REG OUTCOME(R) trial. Eur Heart J. (2016) 37:1526-34. doi: 10.1093/eurheartj/ehv728

32. Radholm K, Figtree G, Perkovic V, Solomon SD, Mahaffey KW, de Zeeuw D, et al. Canagliflozin and heart failure in type 2 diabetes mellitus: results from the CANVAS program. Circulation. (2018) 138:45868. doi: 10.1161/CIRCULATIONAHA.118.034222

33. Wiviott SD, Raz I, Bonaca MP, Mosenzon O, Kato ET, Cahn A, et al. Dapagliflozin and cardiovascular outcomes in type 2 diabetes. N Engl J Med. (2019) 380:347-57. doi: 10.1056/NEJMoa1812389

34. Perkovic V, Jardine MJ, Neal B, Bompoint S, Heerspink HJL, Charytan DM, et al. Canagliflozin and renal outcomes in type 2 diabetes and nephropathy. $N$ Engl J Med. (2019) 380:2295-306. doi: 10.1056/NEJMoa1811744

35. Petrie MC, Verma S, Docherty KF, Inzucchi SE, Anand I, Belohlavek J, et al. Effect of dapagliflozin on worsening heart failure and cardiovascular death in patients with heart failure with and without diabetes. JAMA. (2020) 323:1353-68. doi: 10.1001/jama.2019.22087

36. Packer M, Anker SD, Butler J, Filippatos G, Pocock SJ, Carson P, et al. Cardiovascular and renal outcomes with empagliflozin in heart failure. N Engl J Med. (2020) 383:1413-24. doi: 10.1056/NEJMoa2022190

37. Cannon CP, Pratley R, Dagogo-Jack S, Mancuso J, Huyck S, Masiukiewicz $\mathrm{U}$, et al. Cardiovascular outcomes with ertugliflozin in type 2 diabetes. N Engl J Med. (2020) 383:1425-35. doi: 10.1056/NEJMoa20 04967

38. Heerspink HJL, Stefansson BV, Correa-Rotter R, Chertow GM, Greene T, Hou FF, et al. Dapagliflozin in patients with chronic kidney disease. N Engl J Med. (2020) 383:1436-46. doi: 10.1056/NEJMoa2024816

39. Wanner C, Inzucchi SE, Lachin JM, Fitchett D, von Eynatten M, Mattheus M, et al. Empagliflozin and progression of kidney disease in type 2 diabetes. $N$ Engl J Med. (2016) 375:323-34. doi: 10.1056/NEJMoa1515920

40. Scheen AJ. Cardiovascular effects of new oral glucose-lowering agents: DPP-4 and SGLT-2 inhibitors. Circ Res. (2018) 122:143959. doi: 10.1161/CIRCRESAHA.117.311588 
41. Garber AJ, Abrahamson MJ, Barzilay JI, Blonde L, Bloomgarden ZT, Bush MA, et al. Consensus statement by the American Association of Clinical Endocrinologists and American College of Endocrinology on the comprehensive type 2 diabetes management algorithm - (2019). Executive Summary. Endocr Pract. (2019) 25:69-100. doi: 10.4158/CS-2018-0535

42. Perreault L. EMPA-REG OUTCOME: the endocrinologist's point of view. Am J Cardiol. (2017) 120:S48-s52. doi: 10.1016/j.amjcard.2017.05.010

43. Bistola V, Lambadiari V, Dimitriadis G, Ioannidis I, Makrilakis K, Tentolouris N, et al. Possible mechanisms of direct cardiovascular impact of GLP-1 agonists and DPP4 inhibitors. Heart Fail Rev. (2018) 23:37788. doi: 10.1007/s10741-018-9674-3

44. Scheen AJ. Pharmacokinetic/pharmacodynamic properties and clinical use of SGLT2 inhibitors in non-Asian and Asian patients with type 2 diabetes and chronic kidney disease. Clin Pharmacokinet. (2020) 59:98194. doi: 10.1007/s40262-020-00885-z

45. Ou HT, Chang KC, Li CY, Wu JS. Comparative cardiovascular risks of dipeptidyl peptidase 4 inhibitors with other second- and third-line antidiabetic drugs in patients with type 2 diabetes. Br J Clin Pharmacol. (2017) 83:1556-70. doi: 10.1111/bcp.13241

46. Iorga RA, Bacalbasa N, Carsote M, Bratu OG, Stanescu AMA, Bungau $\mathrm{S}$, et al. Metabolic and cardiovascular benefits of GLP-1 agonists, besides the hypoglycemic effect (Review). Exp Ther Med. (2020) 20:2396400. doi: 10.3892/etm.2020.8714

47. Lyu J, Li Z, Wei H, Liu D, Chi X, Gong DW, et al. A potent risk model for predicting new-onset acute coronary syndrome in patients with type 2 diabetes mellitus in Northwest China. Acta Diabetol. (2020) 57:70513. doi: 10.1007/s00592-020-01484-X

48. Yang Y, Li W, Zhu H, Pan XF, Hu Y, Arnott C, et al. Prognosis of unrecognised myocardial infarction determined by electrocardiography or cardiac magnetic resonance imaging: systematic review and meta-analysis. BMJ. (2020) 369:m1184. doi: 10.1136/bmj.m1184

49. Venuraju SM, Lahiri A, Jeevarethinam A, Cohen M, Darko D, Nair D, et al. Duration of type 2 diabetes mellitus and systolic blood pressure as determinants of severity of coronary stenosis and adverse events in an asymptomatic diabetic population: PROCEED study. Cardiovasc Diabetol. (2019) 18:51. doi: 10.1186/s12933-019-0855-8
50. Hu C, Zhang J, Liu J, Liu Y, Gao A, Zhu Y, et al. Discordance between the triglyceride glucose index and fasting plasma glucose or $\mathrm{HbA1C}$ in patients with acute coronary syndrome undergoing percutaneous coronary intervention predicts cardiovascular events: a cohort study from China. Cardiovasc Diabetol. (2020) 19:116. doi: 10.1186/s12933-020-01091-8

51. Kang J, Kim YC, Park JJ, Kim S, Kang SH, Cho YJ, et al. Increased epicardial adipose tissue thickness is a predictor of new-onset diabetes mellitus in patients with coronary artery disease treated with highintensity statins. Cardiovasc Diabetol. (2018) 17:10. doi: 10.1186/s12933-0170650-3

52. Tan X, Benedict C. Increased risk of myocardial infarction among patients with type 2 diabetes who carry the common rs10830963 variant in the MTNR1B gene. Diabetes Care. (2020) 43:2289-92. doi: 10.2337/dc 20-0507

53. Goodarzi MO, Rotter JI. Genetics insights in the relationship between type 2 diabetes and coronary heart disease. Circ Res. (2020) 126:152648. doi: 10.1161/CIRCRESAHA.119.316065

54. Cziraky M, Pollock M. Real-world evidence studies. 2015[EB/OL].(201704-04). Available online at: https://www.appliedclinicaltrialsonline. com/view/real-world-evidence-studies (accessed December 13, 2020).

55. Tanaka A, Node K. How should we monitor the cardiovascular benefit of sodium-glucose cotransporter 2 inhibition? Cardiovasc Diabetol. (2020) 19:206. doi: 10.1186/s12933-020-01191-5

Conflict of Interest: The authors declare that the research was conducted in the absence of any commercial or financial relationships that could be construed as a potential conflict of interest.

Copyright (C) $2021 \mathrm{Cui}, \mathrm{Liu}, \mathrm{Li}, \mathrm{Xu}$ and Liu. This is an open-access article distributed under the terms of the Creative Commons Attribution License (CC BY). The use, distribution or reproduction in other forums is permitted, provided the original author(s) and the copyright owner(s) are credited and that the original publication in this journal is cited, in accordance with accepted academic practice. No use, distribution or reproduction is permitted which does not comply with these terms. 